Mid-American Review of Sociology

Slusher, Howard S. 1967 Man, Sport and Existence: A Critical Analysis, Lea and Febiger, Philadelphia, Pennsylvania.

Snyder, Eldon E. 1974 "Kickoff", Journal of Popular Culture, Vol.VII:2, Fall

Stone, Greg 1955

"Play and Display", Chicago Review, Fall.

Vanderzwagg, Harold J.

Toward a Philosophy of Sport, Addison-Wesley Publishing Co, Reading, Massachusetts.

Weiss, Paul

1969

Sport, a Philosophic Inquiry, Southern Illinois University Press. Carbondale and Edwardsville.

\section{BEYOND STRUCCTURAL ANALYSIS IN THE SOCIOLOGY OF SOCIOLOGY: THE CASE OF BEHAVIORISM AND ETHNOMETHODOLOGY}

Melvin L. Oliver

Washington University

Mid-American Review of Sociology, 1977, Vol. 2, No. 2:43-66

The paper focuses on an analysis of the potential impact that the behaviorist and ethnomethodological paradigms may have on academic sociology. Structural analysis in the sociology of sociology (Friedrichs, 1974; Mullins, 1973) is criticized and countered with an analysis which stresses the subjective process of theory acceptance and rejection exploiting Gouldner's concept of "domain assumptions"(1970). Utilizing data from a large survey of sociologists queried during the mid-sixties (Sprehe, 1967), the fit between various groupings of sociologists' "domain assumptions" and the "background assumptions" of each theory are analyzed. The results of such an analysis suggest that ethnomethodology may be more attractive to certain groupings of sociologists than behaviorism, thus contradicting in part the argument advanced on the basis of a structural analysis. The paper calls for a recognition of the dialectical interplay between "structural conditions" and "subjective forces" in the adoption and rejection of theory.

\section{INTRODUCTION}

During the latter half of the sixties there emerged a discusssion over which theoretical paradigm would replace sociology's fallen prince, functionalism (Gouldner, 1970; Friedrichs, 1970). This paper explores that question further by

The author wishes to express his appreciation for reading and making suggestions to improve the manuscript to the following: Roberta Arnold, David Sallach, Paul Piccone, Hugh Mehan, Alvin W. Gouldner, and Alan Johnson. All errors in judgment and substance remain those of the author. 
positing a preliminary analysis which attempts to assess the ial attractiveness of "behaviorism" and "ethnomethodology" to various groupings of sociologists. In so doing we will attempt to take the analysis one step further than similar analyses, whose main argument tends to be structurally iented (Friedrichs, 1974; Mullins, 1973). Moreover, the extended analysis presented here attempts to show the "fit" between the "background assumptions" of the particular theories in question and the "domain assumptions" of various groupings of ciologists (Gouldner, 1970:29-35). That the fit between the background assumptions of theory and the domain assumptions of sociologists has a bearing on the careers of theories has been demonstrated by Gouldner who notes that:

... In some part, theories are accepted or rejected because of the ... In some part, theories aredicular, a social background assumptions embedded in the share the theory is more likely to be accepted by those who share the theory's background assumptions and find them agreeable ... social theories and their component concepts contain a charge of surplus meanings derived in part from their background assumptions, and these may congenially resonate the compatible background assumptions of their hearer or may generate a painfu dissonance (Gouldner, 1970:29).

\section{THE STRUCTURAL ARGUMENT}

Those who have attempted a structural analysis of the dominance or potential dominance of particular theoretical orientations within sociology have tended to stress four factors: i) the leaders in the discipline who share that particular orientation, 2) the departments controlled by adherents of the theory in question, 3 ) the books or written materials which serve as "exemplars" of the type of work called for by the theoretical persuasion, and 4) the social, political, and economic contexts as they apply to sociology's need for external material support. The underlying logic of this approach seems to be that theories which are congruent with the material needs of sociology tend to be accepted by the most significant institutions and people in the discipline. The pivotal positions that these institutions and significant figures occupy are important in the socialization of new members into the discipline, thus providing the situational determinants for the acceptance of the theory in question (see Friedrichs, 1974, 1970;Gouldner, 1970; Mullins, 1973).

Utilizing this type of analysis to assess behaviorism's impact on American sociology, Friedrichs has concluded that behaviorism is in an excellent position to "... inherit the claim of sociological 'orthodoxy' in the latter half of the 70's" (1974:3). His reasons include: 1) The "manifest" and "latent" support of behaviorism by leading members of the discipline, namely George C. Homans and James Coleman (Friedrichs, 1974:4-5). 2) The significant number of graduate departments throughout the country which serve as "invisible colleges" where disciples of behaviorism teach and research (Friedrichs, 1974:6-7). 3) The quality of behaviorism's exemplars which convey to the student the rules of the paradigm and concrete research examples; the chief exemplars being Scott's The Internalization of Norms and Homan's Social Behavior (Friedrichs, 1974:6).4) And finally, the potential that behaviorism has in consolidating the position of sociology within the federal funding bureaucracy (Friedrichs, 1974:5; Tarter, 1973:54; Skinner, 1971). This type of analysis provides tentative support for the notion that behaviorism, understood as a competing paradigm, has gained a solid foothold in contemporary sociology and is in an excellent position to extend that status even further.

When ethnomethodology is likewise assessed, the results are not as promising. A structural analysis of ethnomenthodology would point out the following, which contrast greatly with the previous analysis of behaviorism: 1) The organizational and intellectual leaders of ethnomethodology, Aaron V. Cicourel and Harold Garfinkel, do not have hallowed places in academic sociology (Mullins, 1973:198). 2) Ethnomethodologists are rather "ghettoized" in the State University System of California; thus inhibiting access to large numbers of students and potential adherents (Mullins, 1973:192-193). 3) The exemplars of ethnomethodology, Garfinkel's Studies in Ethnomethodology (1967) and Cicourel's Method and Measurement in Sociology 
(1964), are not adequate in conveying the uniqueness and import of the ethnomethodological paradigm. ${ }^{1}$ 4) Alas, ethnomethodology's potential to serve as a drawing card for federal monies is low due to its stress on micro-sociology which does not respond to questions that the federal funding bureaucracy wants answers to, and on the other hand, its propensity to give the wrong answers when responding to questions of social structure, questions that the federal government wants so desperately answered. ${ }^{2}$ Such an analysis obviously must conclude that the ethnomethodological paradigm is in a poor position to assume any semblance of paradigmatic dominance in the discipline of sociology.

\section{CRITIQUE OF THE STRUCTURAL ARGUMENT}

The structural analysis of the potential impact of behaviorism and ethnomethodology on sociology has shown that behaviorism is in a much better position than ethnomethodology to assume is in a much better position the leading theoretical paradigm in the discipline. It is the contention of this author that such an analysis may lead to faulty conclusions when used as the only approach to such a problem. As proof of this let us consider more closely the underlying logic of this approach.

As was shown earlier, a large part of the structural argument rests on the assumption that graduate departments are able to provide the situational determinants whereby students come to accept one theoretical orientation as opposed to others. That this is the case is not at all clear. Graduate students (just as any other person involved in human interaction) do not possess blank minds which are just waiting to be stamped with the proper theoretical perspective or ideology. As human actors they come into a department with at least twenty years of living and association with other people behind them. This association has provided them with a matrix of values, opinions, and beliefs which are held with little or possibly great resistance to change. The structure of the department and the theories that are taught therein are interpreted through the backdrop of this matrix (part of which we have labeled domain assumptions) and thus, values, opinions, and beliefs are ultimately involved in the process of accepting or rejecting a theoretical paradigm. The structural approach presents an over-deterministic and over-socialized conception of human nature that overlooks the active, creative part that humans play in constructing their reality.

Even if we were to grant that a department can shape the theoretical orientation of its students with such tyranny, it becomes problematic as to whether a department could be monolithic enough to do so. The evidence that has been presented elsewhere on the number and significance of the proponents of one theory that are located within certain departments does not constitute evidence for the conclusion that these departments are monolithic in regard to that theoretical perspective (Friedrichs, 1974:4; Mullins, 1973:183-212). For instance, although a chairman of a department such as Homans of Harvard may be behaviorist, it does not logically follow that the department will monolithically represent a behaviorist perspective. Few chairpersons are able to exert such clout, and those who could are forced through the pressures of students and junior faculty to attempt to show some evidence of theoretical pluralism. In so doing they allow the development of competing perspectives that can serve as alternatives for those who are not in favor of reigning perspectives (for a similar argument see Morris and Hesslink, 1974:150).

These criticisms tend to weaken the previous hypothesis regarding the potential impact of behaviorism on sociology, for much of the support for the assertion was built on the fact that behaviorism was gaining a solid following among significant members and departments in the discipline. Before we discount the hypothesis completely, we should try to pinpoint just why behaviorism has been so successful in implanting itself so firmly in the discipline. The obvious reason that this writer sees (and which the structuralist argument brings out) is that it is compatible with the research interests of sociology's material Godfather, the federal government. It is this difference with ethnomethodology that makes its potential impact that much greater. Yet to dwell on such an economic fact would lead us to the acceptance of a one-sided economic deterministic explanation. In order to correct 
this, we should seek an analysis which stresses the subjective dimension which the structuralist argument overlooks.

\section{DOMAIN ASSUMPTIONS AND THEORY}

According to Gouldner, many theories are accepted by social scientists not because they best describe relationships in the empirical world, but because they best describe the empirical world of the social scientists. In other words, because they resonate with the life experiences of the actor. What makes these theories intuitively resonate with our life experiences is that the background assumptions of the theory "coincide or are compatible with, consensually validate or bring to psychic closure, the background assumptions held by the viewer" (Gouldner:30).

The background assumptions of the social scientist may range from beliefs about the world that are very general and liberally applicable, to assumptions of more limited scope and application. These latter are called domain assumptions and are further described by Gouldner as:

\footnotetext{
... background assumptions applied only to members of a single domain; they are, in effect, the metaphysics of a domain. Domain assumptions about man and society might include, for example, dispositions to believe that men are rational or irrational; that society is precarious or fundamentally stable; that social problems will correct themselves without planned intervention; that human behavior is unpredictable; that man's true humanity resides in his feelings and sentiments (Gouldner:31).
}

Gouldner's seminal study (The Crisis) is an attempt to show that domain assumptions do have significant consequences for theory by examining the rise and fall of functionalism, and the crisis of academic and Marxist sociology. Our interests in the concepts of "domain assumptions" and "background assumptions" is to interpret the "fit" between these two as they pertain to various groupings of sociologists in the cases of behaviorism and ethnomethodology. In so doing we will be making use of data collected by Gouldner and Sprehe in the mid-sixties on the values and belief systems of sociologists
(Gouldner and Sprehe, 1967). ${ }^{3}$

\section{The Empirical Background}

In November, 1964, Timothy Sprehe, under the direction and sponsorship of Alvin Gouldner, sent a questionnaire to every individual subscriber of the American Sociological Review, or in other words, the total membership of the American Sociological Association. The goal of the questionnaire was explained as an attempt "to explore the informal beliefs of sociologists concerning research, teaching, and writing and, also, the self-concept of the sociologist himself" (Gouldner and Sprehe, p: 42). The final report, prepared by Sprehe as a doctoral dissertation, contained an analysis of the values and beliefs of sociologists in terms of an occupational ideology. Factor analysis was used to determine the structure of the occupational ideologies of sociologists, and an attempt was made to relate these values and beliefs to the social milieu of sociologists; what is the relationship between a sociologist's values and beliefs, and educational, occupational, political, and religious variables (Sprehe, 1967:53).

One of the variables that Sprehe attempted to isolate and utilize was that of domain assumptions. He did this first by constructing a set of items which he thought clustered together theoretically to be used in the questionnaire. Fifteen items were constructed representing various subthemes about the nature of human behavior. Factor analysis of the results showed that six items clustered together to form a factor called domain assumptions. ${ }^{4}$ These. items were:

Men conduct their lives in a more rational manner than we often think. Many sociologists underestimate the importance of
rationality in human life.

Most people think human behavior is more complex than it really is. 
Mid-American Review of Sociology

Most people think human behavior is simpler than it really is.

Sociological research is often best conducted if treated as a game.

By and large, social problems tend to correct themselves without planned intervention (Sprehe, 1976:260).

These items seem to suggest that assumption about the belief as to whether or not humans conduct their lives in a rational manner and whether or not human behavior is simple or complex consists of the domain assumptions of the group of sociologists queried by Sprehe (a group numbering 3,441). Although there might be other domain assumptions in this same group, these were the only two that were successfully tapped using the method of questionnaire design and validation.

Having found an empirical referent of domain assumptions among members of the sociological profession, we may now compare the background assumptions of our theories in question to see if they differ in any substantial manner with each other on the questions of the rationality of human behavior and its relative simplicity or complexity. ${ }^{5}$ If they do then we may hypothesize the possible consequences by elaborating on the relationships among groups of sociologists that Sprehe found in his sample. An example will better illustrate the procedure. If, in our examination of the background assumptions of behaviorism, we find that it stresses a rational model of human behavior, while ethnomethodology does not; then we can label it as consistent with the domain assumption of rational human action. If dominant sociologists (as defined by Sprehe) also responded positively to this domain assumption then we could say we have found a "fit" between the background assumptions of theory and the domain assumptions of our particular group (dominant sociologists) of sociologists. We could further hypothesize the consequences of such a fit. In this way we provide a corrective to the over-deterministic and over-socialized view presented by the structuralist argument.
Behaviorism and Ethnomethodology

Behaviorism and Ethnomethodology on the Rationality

and Complexity of Human Behavior

Behaviorists have directly commented on the supposed image of rationality that their theory fosters. According to Skinner, the concept of reason itself is "the most admired cognitive or mental process" in the conceptual armory of non-behaviorists. Its status as a "mentalistic construct" leads to its epistemological denial by Skinner. Rationality for Skinner is contained in the evolutionary process with its reinforcement of actions and practices which promotes survival of the species (Skinner, 1974:128-136).

As one moves to the sociological behaviorism of a Homans, the picture changes quite drastically. In the world of "exchange", with its similarity to elementary economics, it is very easy to impute to the actor the same type of interest-oriented rationality that pertains in the economic marketplace. Homans is prepared to accept that this type of rationality exists in some social behavior:

... The social climber is an example. Using his explicit knowledge of the proposition we try to make explicit here, and prepared to accept-this is his characteristic heroism-certain immediate costs in self-respect, he may well wind up in a far higher social position than he would have attained without his calculations and his peculiar asceticism (Homans, 1961:81).

But, this type of rationality does not affect most social behavior, and social scientists need not make such an assumption to properly explain social behavior:

Although calculation for the long run plays its part in human affairs, we make no allowance for it in our propositions, which are to this extent incomplete. We do not rule it out; neither do we rule it in. Our first justification is that we shall not often need it to explain the research results considered in this book. And our second lies in plain sight: calculation for the long run is the exception and not the rule (Homans, 1961:81).

Although these outright denials may be convincing in a superficial manner, the assumption of rationality seems to be 
deeply imbedded in the behaviorist sociology that Homans outlines. This is shown implicitly in Homans' discussion of the similarity of his human exchange propositions to those of elementary economics:

. . Take the Law of Supply in economics: the higher the price of a commodity, the more of it a supplier will sell. This is equivalent to-we dare not say identical with-our proposition: the more valuable the reward gotten by an activity, the more often a man will emit it. For in the Law of Supply the price of the commodity

is the reward obtained by selling it (Homans, 1961:69).

Although Skinner might deny the existence of rationality, and Homans its importance, it is sufficiently clear that their elementary propositions about human behavior contain an implicit assumption about how humans discriminate between stimuli that is very close to the traditional notion of rationality. This notion of rationality posits the objective rationality of human behavior, a rationality completely independent of individual interpretation and of social and historical contexts. Thus behavior or response $\mathrm{R}$ is, other things being equal, always and everywhere linked to stimulus $\mathrm{S}$, so that behavior in the end is predictable on the basis of this objective rationality. This notion is similar to the type of rationality that Sprehe's factor was attempting to tap.

The ethnomethodologists differ from the behaviorists on this assumption. Ethnomethodologists assume that the actor is involved in a continuous process of interpretation; for Garfinkel it - is "documentary interpretation". (Garfinkel, 1967), for Cicourel it is interpretation based on "surface and interpretive rules" (Cicourel, 1970a and 1970b), and for Zimmerman and Pollner, it is interpretation through the members "occasioned corpus" (Zimmerman and Pollner, 1970). The goal that the ethnomethodologists pursue is the attempt to delineate the rules whereby members interpret their situations and thus act. These rules as of yet are unknown and thus the question is left open as to whether human behavior is rationally motivated as in the behaviorist paradigm. In order to get at this point more closely, let us examine the work of Cicourel on this subject.
The problem for Cicourel is that of social order. If members' actions are a consequence of their own interpretations of the situation, then how are common actions possible? In order to solve this dilemma Cicourel employs two concepts borrowed from Chomsky's work on generative grammar, surface rules and interpretive rules (or interpretive procedures). Interpretive rules "provide the actor with a developmentally changing sense of social structure that enables him (the actor) to assign meaning or relevance to an environment of objects" (Cicourel, 1970a:29).

These two types of rules, although analytically separable, interpenetrate each other to provide for a "sense of social structure". Thus this model implies that a sense of social structure or order is made possible whenever interpretive rules are invoked to justify or evaluate a course of action within a context in which several norms or surface rules are possible. As Cicourel notes:

... Hence the learning and use of general rules or norms, and their long-term storage, always require more basic interpretive rules for recognizing the relevance of actual, changing scenes, orienting the actor to possible courses of action, the organization of behavioral displays, and their reflective evaluation by the actor (Cicourel, 1970a:31).

Interpretive rules are invariant, applying to all situations. Their existence makes possible concerted human behavior and they are the basis of the ways in which we cognitively organize our social settings. As a first step in describing these rules, Cicourel has drawn on the work of Alfred Schutz. He notes six features as described by Schutz which could serve as a beginning in delineating the interpretive rules that actors use (this list is in no way exhaustive of all the possible rules):

1. The reciprocity of perspectives.

2. The et cetera rule and its subroutines.

3. The idea of normal form typifications.

4. Retrospective-Prospective scene of occurrence. 
5. Talk itself as reflexive.

6. Descriptive vocabularies as indexical expressions.

(Cicourel, 1970b:147-152).

The purpose of this exegesis of Cicourel's work was to show ethnomethodology's stress on the interpretive process. This highlights a concern with the subjective rationality of human behavior. As opposed to the objective rationality of the behaviorist paradigm, the subjective rationality of ethnomethodology focuses on the "subjectivity" of human behavior, the many possible interpretations that can be advanced, instead of the one objective stimuli that behaviorists point to.

One of the frequent charges leveled against behaviorism by its critics has been that it treats its subject matter in a simplistic manner, thus denying the supposed complexity of human behavior. In commenting on his critics Skinner has rightly shown that behaviorism has been "especially vulnerable to the charge of simplification because it is hard to believe that a fairly simple principle can have vast consequences in our lives" (Skinner, 1974:231). As if to use the same logic as his critics, Skinner turns around and notes that "the experimental analysis of behavior is a rigorous, extensive, and rapidly advancing branch of biology, and only those who are unaware of its scope can call it oversimplified" (Skinner, 1974:231). Though it cannot be said that the complexity of methods used in the study of behavior represents a sure-fire sign of the complexity of the behavior itself, there does seem to be some congruence between the complex or simple way subject matter is approached, and the assumptions made regarding the complexity or simplicity of human behavior. This seems especially true of the conceptual apparatus used in theory and research.

It has been noted by Friedrichs that the conceptual parsimony of behaviorism is tantalizingly attractive to many sociologists (Friedrichs, 1974:3). With a corpus of less than ten well-developed concepts, behaviorists are able to "explain" almost any phenomenon. The assumption that the behaviorist is dealing with the most basic propositions of human behavior adequately conveys the background assumption that human behavior is essentially knowable in all its variations and thus simple to the eyes of the trained behaviorist.

The ethnomethodologist, on the other hand, has a healthy respect for the complexity of human behavor. It is highlighted in the open-ended nature of the theory's self-proclaimed subject matter: the study of the ways in which members make sense of their world.

The most telling fact of ethnomethodology's awareness of the complexity of human behavior is its reliance on the concept of "emergence". The use of the concept emergence displays the recognition of the fact that the actors' definitions of the situation and actions are not settled permanently through the application of a norm or some other pre-existing cultural system but are "interpretations formulated on particular occasions by the interactor and are subject to reformulation on subsequent occasions" (Wilson:69). ${ }^{6}$ Therefore, predictions based on some sort of normative criteria of behavior are impossible. The creative and active potential of the actor is emphasized, exhibiting the richness and complexity of human behavior.

Our analysis has indicated that behaviorism tends to foster a model of human behavior that stresses the objective rationality of human activity. This is closest to the common notion of the concept of rationality in the social sciences whereby it is posited that there is a reason for each action that can be objectively pointed to. Along with this stress on objective rationality is a corresponding belief in the simplicity of human behavior. Ethnomethodology, on the other hand, posits a model of human behavior based on the subjective rationality of human activity. This type of rationality as distinguished from objective rationality, takes rationality as more contingent and subjectively determined, thus positing a multitude of in-order-to motives which lead to social action. ${ }^{7}$ Furthermore, ethnomethodology assumes that human behavior is complex, and highlights that complexity throughout. 


\section{The Fit}

Since the background assumptions of behaviorism and ethnomethodology differ substantially in relation to beliefs about the rationality and complexity of human behavior, we can now compare the fit between these assumptions and the domainassumptions (which also concern beliefs about the rationality and complexity of human behavior) of various groupings of sociologists as polled by Sprehe. On the basis of a fit or non-fit between these two dimensions, we will be able to hypothesize about the tendencies of these groups of sociologists to be favorable toward or resistant to our theories in question.

In the questionnaire, respondents were asked to rate items on a seven-point Likert scale, from Strongly Agree to Strongly Disagree. A high score on an item would indicate agreement with. the theme that the item represented, while a low score would indicate disagreement with the theme. The relevant groupings that we will be considering are those related to the following variables: graduates of prestige and non-prestige schools, academic rank, dominant sociologists, age and political affiliation.

According to Sprehe, respondents who received their highest degree from prestige schools ${ }^{8}$ tended to reject or score low on the items that constituted the factor of domain assumptions. Meanwhile, those from non-prestige schools scored high on this factor (Sprehe, 1967:315). It would seem that those who graduated from prestige schools would find the background assumptions of behaviorism inconsistent with their domain assumptions, thus providing a context in which behaviorism would be rejected. In the same way, graduates of non-prestige schools would be resistant to ethnomethodology's insistence about the non-rationality and complexity of human behavior.

Academic rank showed no clear pattern in the survey. Graduate students, for the most part, did not score high or low on this factor, indicating that they might be inclined to either view, depending on the situational context in which they are presented. This would lend credence to the structural argument which essentially posits the assumption that students are easily steered to a theoretical orientation in the proper context. Non-tenured faculty were found to be polarized at both ends of the scale, one group agreeing with the rationality and simplicity of human behavior and the most numerous group disagreeing. Tenured faculty were also polarized, but more evenly among those disagreeing and agreeing with the rational-simplistic model of human behavior (Sprehe:315). Any interpretation of these facts to our problem would be very tenuous at this time. The one thing that they did show was that there is no clear-cut preference in the academic ranks of tenured and non-tenured faculty that would lead to the majority acceptance of either ethnomethodology or behaviorism on the basis of a fit between their domain assumptions and the background assumptions of the theories.

In order to see if dominant sociologists differed from other sociologist, Sprehe constructed a measure of dominance which included four variables: prestige school of origin, size of employing institution, amount of research funds and an index of professional participation. The findings in regard to domain assumptions and dominance pointed out that dominant sociologists did not hold a rational model of human behavior and did not believe that behavior was essentially simple (Sprehe:317). This finding, when combined with the structural argument, would lend support to the notion that ethnomethodology would receive a better reception among dominant sociologists than behaviorism. The domain assumptions of dominant sociologists resonate with the background assumptions of ethnomethodology to a much greater degree than those of behaviorism.

The variable of age clarifies somewhat the relationship noted earlier between academic rank and domain assumptions. Among graduate students, the younger ages scored higher on this factor. Tenured faculty tended to agree more strongly with the rational-simplistic model as age increased. Non-tenured faculty also started agreeing with this model after age 40 . This relationship held constant even when considering the prestige or non-prestige origin of the respondents higher degree. Age, instead of academic position, seems to have the most to do with whether or not a respondent scores high or low on the factor. The youngest and oldest respondents were most likely to score high on the factor while non-tenured faculty under 40 years of age scored low (Sprehe, 1967:454-456). Therefore, it would seem that the older 
colleagues in the discipline would be more receptive to behaviorism and that their influence on young graduate students early in their graduate careers would be greater.

The final grouping is based on political affiliation. One of the interesting and relevant findings on this variable was that respondents in their twenties tended to score high on the factor, "especially those of more conservative political preference" (Sprehe, 1967:459). The only exception in this age group was those whose political affiliation was listed as socialist. This same pattern emerged in the age 30 to 40 and 40 to 50 age group. As age increased, the socialists' support for the rational-simplistic model increased also (Sprehe, 1967:459). Therefore, one would expect that those younger sociologists whose political orientation is expressly radical would be sympathetic and attracted to the background assumptions of ethnomethodology, while those of liberal-conservative political orientation would be more inclined toward the behaviorist rational-simplistic model. ${ }^{9}$

This analysis has investigated the fit between the domain assumptions of various groupings of sociologists and the background assumptions of ethnomethodology and behaviorism. The findings indicate that sociologists with degrees from non-prestige schools, those that are very young and very old, and those with liberal to conservative political orientation possess the domain assumptions that would resonate with the background assumptions of the behaviorist orientation. Thus, it is quite probable that these sociologists would intuitively accept the behaviorist paradigm. In the same vein, the analysis has shown the sociologists with degrees from prestige schools, sociologists that are dominant, non-tenured faculty younger than 40 , and those with socialistic political affiliation, possess the domain assumptions that would resonate with the background assumptions of ethnomethodology. Therefore, we posit the increased probability of the intuitive acceptance of the ethnomethodological paradigm by these particular groupings of sociologists.

\section{SUMMARY}

This paper has produced two different analyses concerning the viability of behaviorism and ethnomethodology in the assumption of paradigmatic dominance in the field. One analysis which was termed structural, led to the tentative conclusion that behaviorism was in a much better position to assume theoretical dominance in the discipline than ethnomethodology. The other analysis, which concerned the fit between the background assumptions of theory and the domain assumptions of various groupings of sociologists, was less clear-cut than the structural argument, but nevertheless did show that there might be greater support for ethnomethodology than was originally predicted in the structural argument. ${ }^{10}$

The purpose of this paper was to offset the purely structural accounts of theory development that overlook the subjective aspect of theory acceptance and rejection (Friedrichs, 1974; Mullin, 1973). The "behaviorist band wagon" debate that was started by Friedrichs' excellent analysis of behaviorism's effect on sociology (1974), needs to take into consideration that theory is made, accepted, and rejected, in part, on the basis of the "personal reality" of the theoretician; not only on the basis of impersonal structural forces. A complete explanation of theory development would be a dialectical one, which would take into account the interplay between structural forces, the personal realities of the theorist, and the background assumptions of theory itself.

\section{NOTES}

1. The problem with these works as exemplars is that they fail to give us a concrete example of what kind of empirical project the ethnomethodological paradigm demands. Although Garfinkel parades us through his at times ghastly experiments and his equally interesting case of "Agnes", we are still left with very little knowledge about what one does after one becomes an ethnomethodologist. The purely empirical works thus far published also fail to show us what is so unique about an ethnomethodological approach to the empirical world. Ethnomethodology's failure to produce an exemplar that combines both 
a theoretical and empirical example has hindered the potential that ethnomethodology could have through the teaching and training of a new generation of sociologists. The prime candidate for the new exemplar of ethnomethodology seems to be Mehan and Wood's The Reality of Ethnomethodology (1975). The first real ethnomethodological textbook, it attempts to convey to the reader the uniqueness of the ethnomethodological paradigm by divorcing it from all ties with standard sociology; "Sociology and ethnomethodolgy are separate enterprises, engaging different phenomena" (1975:6). Its use as an exemplar is impaired by this very separation of ethnomethodology from sociology.

2. There are actually two sides to the compatibility of ethnomethodology with the federal funding bureaucracy. On one side there are those ethnomethodologists who are concerned mainly with micro-sociology, e.g., how are conversations opened (Schegloff, 1968). It would appear that this type of analysis would be too vague when applied to the macro-social problems of today to make funding ethnomethodology profitable. On the other side are those ethnomethodologists concerned with social structure who are mainly centered around Cicourel. This interest in social structure has taken concrete form in his research on the juvenile justice system (Cicourel, 1968), the schools (Cicourel and Kituse, 1963; Cicourel et al., 1974), fertility (Cicourel, 1974), and most recently, health care delivery systems (Cicourel, 1975). Although this list seems impressive, Cicourel's relationship with the federal funding bureaucracy may well be a short-lived affair. Unlike behaviorism, Cicourelian ethnomethodology will not be able to give the control-oriented information that the-federal government is interested in obtaining (National Science Foundation, 1969). If history can be trusted; it seems that the type of information that has come out of former research by Cicourel and his students has been insidious critiques of the way these structures are organized so as to create the very problems which the government is trying to control (Cicourel, 1968). This type of critique would require more than just piecemeal reform to remedy, thus making the results of such research useless to the federal funding bureaucracy for obvious reasons.
3. Although the discussion draws on Gouldner's elaboration of the concept of domain assumptions, some problematic aspects of this method should be pointed out. Our heavy reliance on this concept short-circuits a larger sociology of knowledge approach which would address how domain assumptions interact with self-interest and life experience and how that interaction modifies the domain assumptions, making any reference to a static concept of domain assumptions impossible. However, in order to do the type of analysis that this paper calls for we must treat domain assumptions as a static concept represented by the answers obtained in the questionnaire given by Sprehe. The author is aware of the changing nature of domain assumptions and does not agree with the picture that Gouldner paints of the similarity between domain assumptions and stereotypes (Gouldner, $1970: 32-3$ ).

4. Sprehe does not use the term "domain assumptions" to characterize this factor. The first term that he used was "metaphysical assumptions concerning man and society" but this title was dropped after it was pointed out that "metaphysics is not commonly applied to man and/or society" (Sprehe, 1967:64). In order to avoid any confusion he changed it to "Metaphorical Assumptions Concerning Men and Society". The definition that Sprehe unfolds (1967:67-74) is consistent with ours (and Gouldner's) and in order to avoid confusion in our analysis we will refer to this factor as "domain assumptions" throughout our discussion.

5. The reader must keep in mind that the utilization of empirical data collected in the mid-sixties can only lead to suggestive relationships on this question. For that reason no attempt is made to present the results in the quantitative fashion that they are found in Sprehe (1967). This re-analysis is meant to serve as an example of the type of analysis that must supplement structural analyses now being done in the sociology of sociology if the complete picture is to be uncovered.

6. For an extended discussion on the concept of emergence, see McHugh's Defining the Situation: The Organization of Meaning in Social Interaction (McHugh, 1968). 
7. From this point on, reference to a rational model of human behavior, is to be understood as an "objectively rational model of human behavior" as opposed to a "subjectively rational model".

8. The decision to place sociologists into categories of graduates of prestige and non-prestige schools was based on the findings of Cartter's (1966) analysis (Sprehe, 1972:200-201).

9. This brings up a very difficult problem concerning the relationship between Marxism and ethnomethodology. Ethnomethodology speaks to an issue which has an old and venerable tradition in Marxism: the problem of reification. Yet, the micro approach of much of ethnomethodology seems to deny the very structures of society which form the basis of traditional Marxist theory; especially the concepts of class and the party. At this point in time most of the communication that has occurred between the two has been hampered by ethnomethodology's denial of structure. The best that can be hoped for is the type of cross-fertilization wherein each borrows from the other what is useful until a point occurs where a real synthesis will be possible (O’Neil, 1975; Sallach, 1973; Habermas, 1970; Schroyer; 1970).

10. Events in sociology seem to be "verifying" this contention. Ethnomethodology has been making continual inroads into academic sociology. Antagonism toward ethnomethodology is certainly still present, as is evidenced by the reception that the profession gave Cicourel's new study on Argentine fertility in Contemporary Sociology (Bumpass, 1975; Driver, 1975). Yet, much of this antagonism seems to represent the anguish of the more positivistically-oriented sociologists who are observing that they are in fact losing ground to ethnomethodology (Coser, 1975). This is not to say that ethnomethodology will assume the dominance that functionalism once enjoyed in the discipline, but rather that it is on the road to assuming the status of a legitimate competing theoretical paradigm in academic sociology.
Behaviorism and Ethnomethodology

\section{REFERENCES}

Bumpass, Larry

1975 Review of Aaron Cicourel, Theory and Method in a Study of Argentine Fertility. Contemporary Sociology 4 (September):474-476.

Cartter, Alan M.

1966 An Assessment of Quality in Graduate Education. Washington, D.C.: American Council of Education.

Cicourel, Aaron V.

1964 Method and Measurement in Sociology. New York: The Free Press.

1968 The Social Organization of Juvenile Justice. New York: Wiley.

$1970 \mathrm{a}$ "Basic and normative rules in the negotiation of status and role." Pp. 4-45 in Hans Peter Dreitzel (ed.), Recent Sociology: No. 2. New York: Macmillan Company.

$1970 \mathrm{~b}$ "The acquisition of social structure: toward a developmental sociology of language and meaning." Pp. 136-168 in Jack D. Douglas (ed.), Understanding Everyday Life. Chicago: Aldine.

1974 Theory and Method in a Study of Argentine Fertility. New York: Wiley Interscience.

1975 Discourse and Text: Cognitive and Linguistic Processes in Studies of Social Structure. Portions of this paper presented at 1975 ASA meetings. To appear in Versus.

Cicourel, Aaron V. and John Kituse

1973 The Educational Decision Makers. Indianapolis: Bobbs-Merrill.

Cicourel, Aaron V., Kenneth H. Jennings, S.H.M. Jennings, et al.

1974 Language Use and School Performance. New York: Academic Press. 
Coser, Lewis A

1975 "Two methods in search of a substance." American Sociological Review 40 (December):691-700.

Driver, Edwin D.

1975 Review of Aaron Cicourel, Theory and Method in a Study of Argentine Fertility. Contemporary Sociology 4 (September):476-481.

Friedrichs, Robert W.

1970 A Sociology of Sociology. New York: The Free Press.

1974 "The potential impact of B.F. Skinner upon American sociology." The American Sociologist Vol. 9 (February):3-8.

Garfinkel, Harold

1967 Studies in Ethnomethodology. Englewood Cliffs, New Jersey: Prentice-Hall.

Gouldner, Alvin W.

1970 The Coming Crisis of Western Sociology. New York: Basic Books.

Gouldner, Alvin W. and J. Thimothy Sprehe

1965 "The study of man 4: sociologists look at themselves." Trans-Action, Vol. 2 (May and June):42-44.

Habermas, Jurgen

1970 "Toward a theory of communicative competence." Pp. 114-148 in Hans Peter Dreitzel (ed.), Recent Sociology: No. 2 New York: Macmillan Company.

Homans, George Casper

1961 Social Behavior: Its Elementary Forms. New York: Harcourt, Brace and World.

McHugh, Peter

1968 Defining the Situation. Indianapolis: Bobbs-Merrill.
Mehan, Hugh and Houston Wood

1975 The Reality of Ethnomethodology. New York: Wiley Interscience.

Morris, Monica B. and George K. Hesslink

1974 "The potential impact of B.F. Skinner upon American sociology: some further considerations." The American Sociologist, Vol. 9 (August):149-153.

Mullins, Nicholas J.

1973 Theories and Theory Groups in Contemporary Sociology. New York: Harper and Row.

National Science Foundation

1969 Knowledge into Action; Improving the Use of the Social Sciences. Washington, D.C.: Government Printing Office.

O'Neil, John

1975 Making Sense Together: An Introduction to Wild Sociology. New York: Harper Torchbooks.

Sallach, David L.

1973 "Class consciousness and the everyday world in the work of Marx and Schutz." Insurgent Sociologist 3 (Summer):27-37.

Schegloff, Emmanuel

1968 "Sequencing in conversational openings." American Anthropologist. 70:1075-1095.

Schroyer, Trent

"Toward a critical theory for advanced industrial society." Pp. 209-234 in Hans Peter Drietzel (ed.), Recent Sociology: No. 2 New York: Macmillan Company.

Seott, John Finley

1971 The Internalization of Norms, A Sociological Theory of Moral Commitment. Englewood Cliffs, New Jersey: Prentice-Hall. 
Mid-American Review of Sociology

Skinner, B.F.

1971 Beyond Freedom and Dignity. New York: Vintage Books.

1974 About Behaviorism. New York: Alfred A. Knopf.

Sprehe, John Timothy

1967 "The climate of opinion in sociology: a study of the professional value and belief systems of sociologists." Unpublished Ph.D. dissertation. St. Louis: Washington University.

Tarter, Donald E.

1973 "Heeding Skinner's call: toward the development of a social technology." The American Sociologist, Vol. 8 (November):153-158.

Wilson, Thomas $\mathrm{P}$.

1970 "Normative and interpretive paradigms in sociology." Pp. 57-79 in Jack D. Douglas (ed.), Understanding Everyday Life. Chicago: Aldine.

Zimmerman, Don H. and Melvin Pollner

1970 "The everyday world as a phenomenon." Pp. 80-103 in Jack D. Douglas (ed.), Understanding Everyday Life. Chicago: Aldine.

\section{NOTES AND COMMENTS}

Dear Editor:

Herewith submitted for consideration for the inclusion in MARS is "A Guide to the Perplexed". I don't claim profound originality to the contents, but many students have said that they found it useful.

1. Write as if explaining to your graduate student peers-persons at about your level of preparation (or somewhat lower) but without your knowledge of the particular subject matter. Don't address yourself to your professor, as you will usually assume he is more sophisticated than he is, and you will not enunciate the elementary truths that require to be said.

2. Proceed as if writing a "working paper" or "research report." Try to write clearly, simply, precisely, describing exactly what you are finding out. Or, to put it negatively, do not try to write a brilliant essay and, above all, do not imitate the abominably turgid style characteristic of many social scientists.

3. It is more important to be accurate, precise, and honest, than to be original, creative, or insightful. Tell it like it is. Telling it like it is may prove to be the thing most useful.

4. Experience and thought are multidimensional; writing is linear. Write about one thing at a time, then go on to the next thing. Translating the multidimensional into the linear sequential is one of the most difficult elements to acquire of good writing style.

5. It is easier to refine a written draft than it is to translate inchoate thoughts directly into a finished report. Hence, write-however poorly and disorganizedly-but then rewrite, edit, and rewrite again. . . and rewrite again. ... and again. But you cannot rewrite unless first you write. 